\title{
Examining the Correlation of Self-reflect and Mental Health through Path and Significance of Indirect Effect Model
}

\section{자기성찰과 정신건강 간의 경로 및 간접효과유의성 모델탐색}

Se La Lim ${ }^{1}$, Hee Jung Lee ${ }^{2}$, Sun Hee Kim ${ }^{3}$

임세라 ${ }^{1}$, 이희정 ${ }^{2}$, 김선희 $^{3}$

${ }^{1}$ Professor, Department of Clinical Psychology, NungIn University, South Korea, sera325@nate.com

${ }^{2}$ Student, Department of Naturopathic, Dongbang Culture University, Korea, anahjlee57@naver.com ${ }^{3}$ Assistant Professor, Buddhist Department, NunginUniversity, Korea, bindeul5@niu.ac.kr

Corresponding author: Sun Hee Kim

\begin{abstract}
This study explored correlation between self-reflect and mental health with adults of the seoul city and Gyeonggi-do, though a path model and significance of indirect effect model of multifactor mindfulness and mindfulness-self-efficacy. To this end, data were collected from 170 out of 162 survey responses. The survey consisted of five scales measuring the following: the self-reflect, the symptom checklist-90-revised(SCL-90-R), the multi-factor mindfulness(MMSA), and the mindfulness -self-efficacy(MSES). The results were analyzed by M-Plus 6.12 program. To verify average and standard deviation of variables and path model and significance of indirect effect model of how Selfreflect leading to Mental Health through Multi-factor Mindfulness and mindfulness-self-efficacy, the author used bootstrapping methods. For the research result, this study presented descriptive statics for each variable of respondents and conducted correlation analysis among Self-reflect leading to mental health through multi-factor mindfulness $(\beta=-0.136, \mathrm{CI}[-0.207 \sim-0.081])$ and self-reflect leading to mental Health through mindfulness-self-efficacy $\beta=0.125$, CI[0.014 0.321]). Furthermore, the significance of indirect effect model showed significant relationships among self-reflect and multifactor mindfulness and mindfulness-self-efficacy and mental health. However, the path model and significance of indirect effect model on the relationship among Self-reflect and Multi-factor Mindfulness and mindfulness-self-efficacy and Mental Health was verified and suggested as well. Afterwards, the author discussed the contribution and limitation of this study, and suggestions for further research.
\end{abstract}

Keywords: Self-reflect, Multi-factor Mindfulness, Mindfulness-Self-efficacy, Mental Health

요약: 본 연구는 자기성찰과 정신건강 간의 마음챙김 다요인 및 마음챙김 자기효능감의 경로모델 및 간접효과 유의성모델 검증을 위한 측정을 목적으로 하였다. 이에 서울과 경기도의 성인남녀 170 명의 설문지 중에서 불성실한 응답을 제외한 162 명의 자료를 분석하였다. 연구도구는 자기성찰, 마음챙김 다요인과 마음챙김 자기효능감을 사용하였고, 정신건강측정을 위해서는 간이정신진단검사를 사용하였다. 자료분석은 M-Plus 6.12이다. 자기성찰이 정신건강에 이르는 영향에서 마음챙김다요인과 마음챙김자기효능감의 경로모형과

Received: March 28, 2021; 1st Review Result: May 12, 2021; 2nd Review Result: July 01, 2021 Accepted: July 31, 2021 
간접효과유의성 검증을 위해 브스트래핑을 활용한 분석을 하였다.

연구결과로는 자기성찰과 정신건강사이의 마음챙김 다요인 경로가 유의미한 것으로 확인되었다( $\beta=-0.136, \quad \mathrm{CI}[-0.207 \sim-0.081])$. 그리고 자기성찰과 정신건강사이의 마음챙김 자기효능감 경로가 유의미한 것으로 확인되었다 $\beta=0.125, \mathrm{CI}[0.014 \sim 0.321])$. 이에 자기성찰이 마음챙김 다요인과 마음챙김 자기효능감을 매개로하여 정신건강에 이르는 경로의 간접효과 유의성 검증은 유의한 것으로 나타났다. 이에 자아성찰이 마음챙김다요인과 마음챙김자기효능감을 거쳐 정신건강에 이르는 경로가 검증됨이 확인되었다. 이에 후속연구를 위한 제한점과 제언을 제시하고자 한다.

핵심어: 자기성찰, 정신건강, 마음챙김다요인, 마음챙김자기효능감

\section{1. 서론}

최근 마음챙김이 자기성찰과 관련이 있고 정신건강을 증진시킨다는 경험적 증거들에 대 한 연구가 활발하게 진행되고 있다[1]. 또한 마음챙김을 통해 현실을 좀 더 이해하게 되 면 마음을 다스리는 힘이 좀 더 촉진된다고 보고된다[2]. 이는 마음챙김이 인간의 삶에서 빈번히 일어나는 스트레스 상황에 대한 부정적인 느낌과 생각을 멈추어 바라보고 알아차 리게 하는 기능을 하기때문이다. 즉 마음챙김은 정신건강을 위한 대처방안이 될 수 있다 는 의미이다.

마음챙김의 구성요소들은 인지적 자기관찰과 자아실현을 촉진시켜 정신건강에 이르게 한다. 특히 마음챙김다요인은 개인의 내·외 경험에 대한 주의, 자각 및 의식을 통하여 수 용적인 태도를 기를 수 있는 역동적인 심리작용이 될 수 있다. 그리고 마음챙김을 통해 자기효능감이 증진됨으로써 정신건강을 조력하는 의식과 태도가 될 수 있으며 주의, 자 각, 재지향성, 개방성 및 자기수용의 기반이 된다. 이에 자신의 인지, 정서, 행동에 주의 를 기울이게 됨으로써 자신에 대해 명확하게 경험하도록 하는 마음챙김은 정신건강을 도 모한다. 무엇보다도 마음챙김은 자기성찰과 정신건강에 관련이 있으므로 다양한 정신건 강 개입법으로 상담 및 임상현장에서 관심이 집중되고 있다. 이에 서양에서는 마음챙김 에 관한 이론을 개발하여 적용하고있는 의료센터가 활발히 운영되고 있다. 또한 자기성 찰, 마음챙김은 현대인들의 심리 및 신체 질환의 예방과 치료 및 예후 관리 등을 촉진하 는 정신건강 접근 방법으로 보고되고 있다. 즉, 마음챙김은 자기성찰과 정신건강과 관련 이 있음이 입증하고 있기에 임상 및 상담현장에서 심리치료적으로 적용된다. 이러한 증 거는 자기성찰이 마음챙김을 통해 개인 안에서 일어나고 있는 여러 가지 생각이나 감정 등에 몰입하게 하며 내면세계에 몰입하고 집중함으로써 정신건강을 돕는 기제로 나타나 기때문이다[1]. 이에 자아성찰로써 건강한 자아감을 형성하도록 하여 정신건강을 유지하 도록 힘써야한다. 이때 타인과의 소통에서 필요한 끊임없는 내적 물음을 통한 자기확인 과정으로써 마음챙김이 필요하다. 이로써 삶에서 함께 공존하는 타인에 대한 존중과 사 회적 자아로서의 역할에 대한 알아차림이 촉진되고 행위변화를 통해 평안과 행복에 이르 게하여 정신건강을 얻게 된다.

자기성찰은 자신 및 타인탐색으로 자신과 타인의 생각, 감정, 욕구 등을 자각하고, 적극 적으로 탐색하여 자신과 타인의 생각, 감정, 욕구를 이해하거나 변화를 달성함으로써 정 신건강에 이를 수 있다. 더불어 자기성찰을 통해 자기에 대한 앎의 영역을 확장해 나가 는 동시에 타인을 배려하고 타인과의 관계 속에서의 자기를 명확히 인식해 나감으로써 
마음챙김과 정신건강을 찾을 수 있다[2]. 이때 정신건강은 마음챙김을 통해 인간은 자신 의 내면세계에 대하여 비판단 지각을 수행함으로써 있는 그대로의 경험과 자기 자신의 인식의 틀의 근원적인 모습 자체를 객관적으로 볼 수 있게 된다[3]. 그러므로 마음챙김을 통해 자기성찰과 정신건강수준을 높일 수 있다[4].

정신건강과 마음챙김이 상관관계를 보인다는 연구결과를 통해 유추해 볼 때, 마음챙김 이 심리적 증상이나 정신장애의 발병과 유지과정에서 일완종의 보호요인으로 작용할 가 능성을 시사한다[5]. 무엇보다도 마음챙김은 정신건강 문제를 완화하는데 효과가 있다는 연구결과는 다양한 이론들에 의해 제시되었다[6]. 그러나 지금까지 국내에 소개된 마음챙 김요인들은 매우 다양한데 반해 구체적으로 마음챙김의 다요인과 마음챙김을 통한 자기 효능감증진이 자기성찰 및 정신건강과 관련이 있다는 점에 대해 면밀히 분석한 자료들은 부족한 실정이다.

이에 본 연구에서는 한국 성인남녀들을 대상으로 설문조사를 하여 그들이 자기성찰을 통해 정신건강을 이루고 있는지 확인하고 그러한 과정에서 마음챙김 다요인과 마음챙김 자기효능감이 중요한 작용을 할 수 있는지 확인하고자 한다.

\section{2. 연구방법}

\section{1 연구대상}

본 연구를 위해 2019년10월 초부터 2020년 1월 말까지 경기도 및 서울특별시에 거주하는 한국성인남녀 170 명에게 설문지를 배포한 후 불성실하게 응답된 설문지를 제외하고 최종 162 명의 자료를 사용하였다. 이에 대한 연구참여자에 대한 정보는 다음에 나타내었다[표 1].

\subsection{1 연구참여자의 성별}

연구참여자의 성별은 남성 79 명(48.8\%), 여성 83 명 (51.2\%)로 나타났으며, 다음에 나타내었다[표 1].

[표 1] 연구참여자의 성별

[Table 1] The Gender of the Participants $(\mathrm{N}=162)$

\begin{tabular}{|c|c|c|}
\hline Gender & N & $\%$ \\
\hline Males & 79 & 48.8 \\
\hline Females & 83 & 51.2 \\
\hline Total & 162 & 100 \\
\hline
\end{tabular}

\subsection{2 연구참여자의 연령}

연구참여자의 연령은 20대 25명(15.4\%), 30대 29명(18.0\%), 40대 31명(19.1\%), 50대 45명 (27.8\%), 60대 32명(19.7\%)으로 다음에 나타내었다[표 2]. 
[표 2] 연구참여자의 연령

[Table 2] The Age of the Participants ( $\mathrm{N}=162)$

\begin{tabular}{|c|c|c|}
\hline Age & N & $\%$ \\
\hline $20-29$ & 25 & 15.4 \\
\hline $30-39$ & 29 & 18.0 \\
\hline $40-49$ & 31 & 19.1 \\
\hline $50-59$ & 45 & 27.8 \\
\hline $60-69$ & 32 & 19.7 \\
\hline Total & 162 & 100 \\
\hline
\end{tabular}

\subsection{3 연구참여자의 직업}

연구참여자의 직업에 관한 정보는 회사원 15 명(9.3\%), 자영업자 30 명 (18.5\%), 공무원 31 명(19.1\%), 영업사원 48 명(29.7\%), 가정주부 23 명 (14.2\%), 교수 명(3.0\%), 교사 10 명(6.2\%)로 나타났으며, 다음에 나타내었다[표 3].

[표 3] 연구참여자의 직업

[Table 3] The Job of the Participants $(\mathrm{N}=162)$

\begin{tabular}{|c|c|c|}
\hline Job & $\mathrm{N}$ & $\%$ \\
\hline Conpany Employee & 15 & 9.3 \\
\hline Independent business owners & 30 & 18.5 \\
\hline Government official & 31 & 19.1 \\
\hline Saleman & 48 & 29.7 \\
\hline Housewife & 23 & 14.2 \\
\hline Professor & 5 & 3.0 \\
\hline Teacher & 10 & 6.2 \\
\hline Total & 162 & 100 \\
\hline
\end{tabular}

\subsection{4 연구참여자의 소득}

연구참여자의 년간 소득은 2500 만원이하가 35 명(21.6\%), 3000 만원이하가 45 명 (27.8\%), 3500 만원이하가 47 명(29.0\%), 4000 만원이하가 32 명(19.8\%), 4500 만원이하가 30 명(18.5\%), 5000 만원 이상이 20 명(12.3\%)으로 나타났으며 다음에 나타내었다[표 4].

[표 4] 연구참여자의 년간 소득

[Table 4] The Annual Income of the Participants (N=162)

\begin{tabular}{|c|c|c|}
\hline Anual & $\mathrm{N}$ & $\%$ \\
\hline Less than $25,000,000(\mathrm{KRW})$ & 35 & 21.6 \\
\hline Less than $30,000,000(\mathrm{KRW})$ & 45 & 27.8 \\
\hline
\end{tabular}




\begin{tabular}{|c|c|c|}
\hline Less than $35,000,000(\mathrm{KRW})$ & 47 & 29.0 \\
\hline Less than $40,000,000(\mathrm{KRW})$ & 32 & 19.8 \\
\hline Less than $45,000,000(\mathrm{KRW})$ & 30 & 18.5 \\
\hline More than $50,000,000(\mathrm{KRW})$ & 20 & 12.3 \\
\hline Total & 162 & 100 \\
\hline
\end{tabular}

\section{2 연구도구}

\subsection{1 자기성찰}

자기성찰(Self-ReflectionScale: SRS)은 자신과 타인의 생각, 감정, 욕구 등을 자각하고, 적 극적으로 탐색하여 자신과 타인의 생각, 감정, 욕구를 이해하거나 변화를 갖는 것을 지칭 한다. 자기성찰은 자기성찰 척도는 4 개 요인으로 자기탐색, 자기이해, 타인탐색, 타인이해 로 4요인이고, 척도의 문항 수는 각 요인 당 5문항, 총 20문항이다[7]. 본 연구에서는 전 체 문항의 평균점수를 사용하여 분석에 사용하였으며, 신뢰도 계수는 .968로 나타났다.

\subsection{2 마음챙김다요인}

마음챙김 다요인 척도(Multi-factor Mindfulness Scale for Adolescents: MMSA)는 마음챙김 다 요인 척도는 의식차원과 태도차원으로 분류된다. 의식은 주의, 자각을 포함하고, 태도는 재지향성, 개방성, 자기수용을 포함한다. 이에 마음챙김다요인이란 2 개 차원 5 개 하위 요 인으로 구성, 총 19 문항이다[8]. 본 연구에서는 전체 문항의 평균점수를 사용하여 분석에 사용하였으며, 신뢰도 계수는 .928로 나타났다.

\subsection{3 마음챙김자기효능감}

마음챙김 자기효능감 척도(Mindfulness-Based Self-Efficacy Scale: MSES)는 행동(Behavior), 인지(Cognition), 내수용기 감각(Interoception), 정서(Affect), 대인관계(Interpersonal), 회피 (Avoidance), 그리고 마음챙김(Mindfulness)의 7개의 하위요인으로 구성되었으며, 각 하위척 도는 5문항씩으로 전체 35문항이다[9]. 본 연구에서는 전체 문항의 평균점수를 사용하여 분석에 사용하였으며, 신뢰도 계수는 .943로 나타났다.

\subsection{4 정신건강}

정신건강은 간이정신진단검사(Symptom Checklist-90-Revision: SCL-90-R)라는 표준화 된 도구를 사용하였다. 이 검사는 90 개 문항으로 구성되어 있으며, 각각의 문항들은 신체화, 강박증, 대인예민성, 우울증, 불안, 적대감, 공포불안, 편집증, 정신증의 9 개 증상척도로 나뉜다[10]. 이 도구는 표준화된 측정도구이므로 별도의 신뢰도 계수를 산출하지않고 기존의 표준화된 도구에서 결정된 전체문항에 대한 평균점수로 분석하였다.

\section{3 자료분석}

조사도구의 신뢰도를 구하기 위해 Cronbach's a계수를 산출하였고, M-Plus 6.12프로그램을 활용하여 매개효과, 경로모형 및 간접효과유의성검증을 하였다. 이에 Bootstrapping에 의해 추정된 경험적 분포의 기준에 따르고자 $95 \%$ 의 신뢰구간을 사용하고, 모집단의 분포를 모 
르는 경우 표본을 $95 \%$ 신뢰구간이 0 을 포함하지 않을 경우에는 통계적으로 유의미하다 고 해석하는 기준에 따라 분석하였다[11].

\section{3. 연구결과}

\section{1 연구변인들의 상관분석}

본 상관분석의 결과를 제시해보면 마음챙김 다요인은 마음챙김 효능감 $(\mathrm{r}=.165, \mathrm{p}<.05)$, 자 아성찰 $(\mathrm{r}=.553, \mathrm{p}<.01)$ 과 유의미한 정적인 상관관계를 나타냈으며, 정신건강 $(\mathrm{r}=-.319, \mathrm{p}<.01)$ 과는 유의미한 부적인 상관관계를 나타냈다. 마음챙김 효능감은 자기성찰 $(\mathrm{r}=.419, \mathrm{p}<.01)$, 정신건강 $(\mathrm{r}=.189, \mathrm{p}<.05)$ 과 유의미한 정적인 상관관계를 나타냈다. 이와 같이 나타난 본 연 구의 변인들은 다음에 나타내었다[표 5].

[표 5]상관분석

[Table 5] Correlation Analysis

\begin{tabular}{|c|c|c|c|c|}
\hline & $\begin{array}{c}\text { Multi-factor } \\
\text { Mindfulness }\end{array}$ & $\begin{array}{c}\text { Mindfulness- } \\
\text { self-efficacy }\end{array}$ & $\begin{array}{c}\text { Self } \\
\text { reflect }\end{array}$ & $\begin{array}{c}\text { Mental } \\
\text { health }\end{array}$ \\
\hline Multi-factor mindfulness & 1 & & & \\
\hline Mindfulness-Self-efficacy & $.165^{*}$ & 1 & 1 & \\
\hline Self reflect & $.553^{* *}$ & $.419^{* *}$ & .056 & 1 \\
\hline Mental health & $-.319 * *$ & $.189 *$ & .056 \\
\hline
\end{tabular}

\section{2 경로모형}

자기성찰과 정신건강의 사이에서 마음챙김 다요인및 마음챙김 효능감의 간접효과유의성 검증을 하는 과정에서 필요한 매개효과탐색 및 경로모형을 확인하고자, 통계적 검증을 하였다. 이에 자기성찰은 마음챙김 다요인 $(\beta=467, \mathrm{t}=3.691, \mathrm{p}<.001)$ 과 마음챙김 효능감 $(\beta$ $=.360, \mathrm{t}=4.189, \mathrm{p}<.001)$ 에 유의한 정적 영향을 주는 변인임이 확인되었다. 마음챙김 다요인 은 정신건강 $(\beta=-.376, \mathrm{t}=4.565, \mathrm{p}<.001)$, 에 유의한 부적 영향을 주는 변인임이 확인되었고, 마음챙김 효능감은 정신건강 $(\beta=.266, \mathrm{t}=2.447, \mathrm{p}<.01)$, 에 유의한 정적 영향을 주는 변인이 라는 것을 알 수 있었다. 이에 자기성찰과 정신건강사이의 마음챙김다요인과 마음챙김자 기효능감의 간접효과유의성검증을 하기 앞선 절차로써 경로모형 및 매개효과를 확인할 수 있는 연구결과를 다음에 나타내었다[표 6][그림1].

[표 6] 경로모형

[Table 6] Path Model

\begin{tabular}{|c|c|c|c|c|c|c|c|}
\hline \multicolumn{2}{|c|}{ Path } & B & B & S.E & t & p \\
\hline Self-reflect & $\rightarrow$ & $\begin{array}{c}\text { Multi-factor } \\
\text { Mindfulness }\end{array}$ & 0.383 & .360 & 0.086 & $4.189 * * *$ & 0.000 \\
\hline Self-reflect & $\rightarrow$ & $\begin{array}{c}\text { Mindfulness- } \\
\text { Self-efficacy }\end{array}$ & 0.305 & .467 & 0.127 & $3.691 * * *$ & 0.000 \\
\hline
\end{tabular}




\begin{tabular}{|c|c|c|c|c|c|c|c|}
\hline $\begin{array}{c}\text { Multi-factor } \\
\text { Mindfulness }\end{array}$ & $\rightarrow$ & Mental Health & -0.347 & -.376 & 0.083 & $-4.565 * * *$ & 0.000 \\
\hline $\begin{array}{c}\text { Mindfulness- } \\
\text { Self-efficacy }\end{array}$ & $\rightarrow$ & mental Health & 0.401 & .266 & 0.108 & $2.447 *$ & 0.014 \\
\hline \multicolumn{7}{|c|}{$* \mathrm{p}<.05 * * \mathrm{p}<.01 * * * \mathrm{p}<.001$} \\
\hline
\end{tabular}

[그림1] 매개효과

[Fig. 1] Mediation Effect

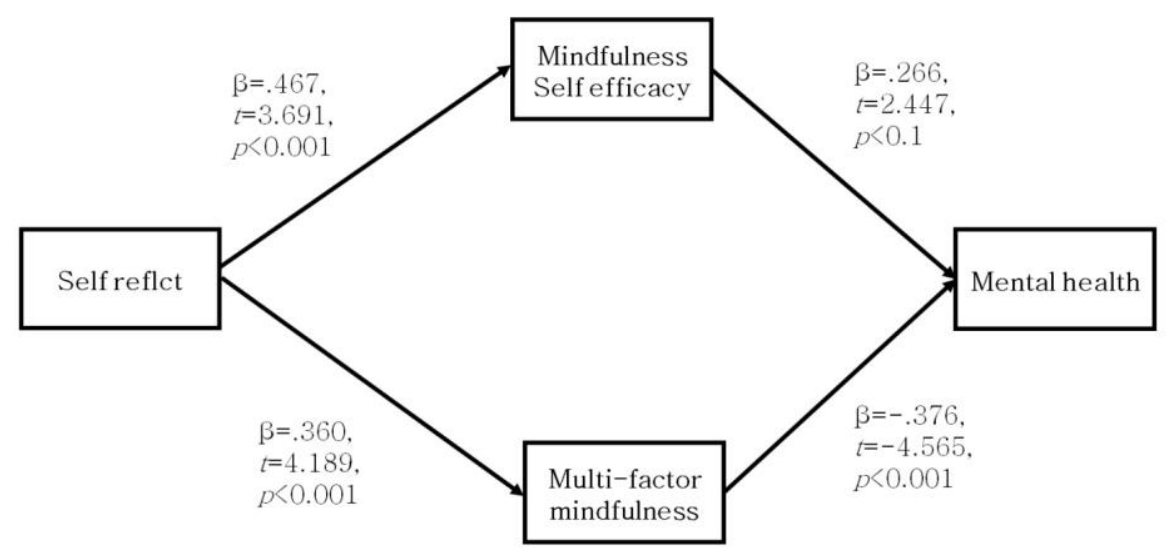

\section{3 간접효과유의성검증}

자기성찰과 정신건강의 사이에서 마음챙김 다요인 및 마음챙김 효능감의 간접효과 유 의성 검증을 하기위하여 bootsrapping으로 통계적 검증 절차를 거쳤다[12]. 이에 자기성찰 의 정신건강에 주는 영향에서 총 효과 $(\beta=-.011, \mathrm{p}=.884)$ 와 총 간접효과( $\beta=-.012, \mathrm{p}=.884)$ 는 유의미하지 않음이 확인되었다. 그러나 자기성찰이 마음챙김 다요인을 거쳐서 정신건 강에 이르는 경로에서는 간접효과의 $95 \%$ 신뢰구간에서 0 을 포함하고 있지 않기 때문에 부적으로 유의미 $(\beta=-0.136, \mathrm{CI}[-0.207 \sim-0.081])$ 했으며, 자기성찰이 마음챙김 효능감을 거쳐 서 정신건강에 이르는 경로에서는 간접효과의 $95 \%$ 신뢰구간에서 0 을 포함하고 있지 않으 므로 정적으로 유의미함을 확인할 수 있었다 $(\beta=0.125, \mathrm{CI}[0.014 \sim 0.321])$. 이에 자기성찰과 정신건강의 관계에서 마음챙김 다요인과 마음챙김 자기효능감의 간접효과 유의성 검증결 과는 다음과 같다[표 7].

[표 7] 간접효과유의성 모델

[Table 7] Significance of Indirect Effect Model

\begin{tabular}{|c|c|c|c|c|c|}
\hline \multicolumn{3}{|c|}{ Path } & Total effect & $\begin{array}{c}\text { Total indirect } \\
\text { effect }\end{array}$ & $\begin{array}{c}\text { Indirect effect } \\
\text { [bootstrapping CI 95\%] }\end{array}$ \\
\hline \multirow{2}{*}{$\begin{array}{l}\text { Self } \\
\text { reflect }\end{array}$} & $\begin{array}{l}\text { Multi-factor } \\
\text { Mindfulness }\end{array}$ & \multirow{2}{*}{$\begin{array}{l}\text { Mental } \\
\text { Health }\end{array}$} & \multirow{2}{*}{-.012} & \multirow{2}{*}{-.012} & $\begin{array}{c}-0.136 \\
{[-0.207 \sim-0.081]}\end{array}$ \\
\hline & $\begin{array}{l}\text { Mindfulness- } \\
\text { Self-efficacy }\end{array}$ & & & & $\begin{array}{c}0.125 \\
{[0.014 \sim 0.321]}\end{array}$ \\
\hline
\end{tabular}




\section{4. 결론}

본 연구에서는 상관분석 결과 자기성찰, 마음챙김 다요인, 마음챙김 효능감, 정신건강 은 모두유의미한 상관관계를 나타냈다. 매개효과검증을 통한 경로모형분석의 결과에서는 자아성찰은 마음챙김 다요인과 마음챙김 효능감에 유의미한 영향을 미치는 것으로 나타 났다. 또한, 마음챙김 다요인은 정신건강에 유의미한 영향을 미치는 것으로 나타났으며, 마음챙김 효능감은 정신건강에 유의미한 영향을 미치는 것으로 나타났다.

자기성찰과 정신건강의 관계에서 마음챙김 다요인과 마음챙김 효능감의 간접효과 유의 성 검증에서는 자아성찰의 정신건강에 주는 영향에서 총효과와 간접효과는 유의미하지않 았으나, 자아성찰이 마음챙김 다요인과 마음챙김 효능감을 경유하여 정신건강에 이르는 간접효과는 유의한 것으로 나타났다.

이러한 점은 임윤희와 김종두(2019)와 용홍출(2006)의 연구에서 주장한 바와 같이 마음 챙김의 근원이 되는 자기성찰을 할 수 있는 기회를 가져야한다는 점과 자기성찰과 마음 챙김을 통해 자신의 감각, 사고, 정서등을 인식하는 마음챙김을 해 나가는 것이 핵심[1][4] 이라는 점이 확인되었다. 그리고 유영희(2018)와 박성현(2008)의 연구에서 주장한 바와같 이 스스로의 내면적 가치 및 타인과의 대인관계에 대한 열린 마음에 대한 자기성찰로써 살아가면서 겪는 다양한 심리적 문제를 극복하여 정신건강에 이를 수 있는 긍정적인 내 면세계에 대한 자각이 필요함을 알 수 있었다[2][5]. 즉, Baer(2003)와 Shapiro(2006)의 주장 과 같이 인간이 지닌 다양한 정신건강의 형태는 자기이해와 탐색이라는 자기성찰에서 기 인하며 피상적이고 모호한 마음다스리기가 아닌 구체화한 마음의 다양한 측면을 통해 정 신건강에 이를 수 있음을 확인할 수 있었다[3][6].

이로써 본 연구는 자기성찰은 마음챙김에 영향을 주며 다양한 정신건강의 영역을 조력 한다는 선행연구를 다시 한번 더 확인할 수 있었다[13].

현재 국내에서의 정신건강을 조력할수 있는 요인으로 마음챙김과 자기성찰이 효과적이 라는 주장이 빈번히 거론되고 있다. 그러나 대부분이 면밀한 양적검증에 관한 절차를 생 략한 채로 주관적인 주장을 하는 경우가 빈번히 발견되고 있는 상황에서 본 연구는 다음 과 같은 의의를 지닌다.

첫째, 한국의 성인남녀에게 자아성찰과 마음챙김다요인과 마음챙김 자기효능감을 통해 심리적 개입이 중요한 변인으로 작용할 수 있음을 확인하였다는데 의의가 있다.

둘째, 한국의 성인남녀에게 자아성찰이 정신건강에 이르는 경로에서 중요한 변인으로 작용할 수 있음을 확인하였다는데 의의가 있다.

셋째, 임상심리학적으로 중요한 의미를 지니는 연구주제이나 그동안 시도되지않았던 자아성찰이 마음챙김다요인과 마음챙김자기효능감을 거쳐 정신건강에 이르는 매개효과, 경로모형 및 간접효과유의성 검증을 확인하였다는데 의의가 있다.

넷째, 구체적이고 표준화된 정신건강측정도구를 사용하지않고 마음챙김요인에 영향을 준다고 보고되어왔던 선행연구들의 한계를 보완했다는데 의의가 있다.

다섯째, 마음챙김요인에 대해 명료히 측정하기위하여 구체적인 하위요인들을 확인할 수 있는 마음챙김 다요인과 마음챙김 자기효능감을 포함한 연구도구를 활용하여 접근 했 다는 데 의의가 있다.

이와 같은 연구결과를 볼 때 자기성찰이 마음챙김 다요인과 마음챙김 자기효능감의 경 로를 거쳐 한국성인들의 정신건강에 이르도록 적절한 개입을 한다면 임상 및 상담현장에 서 상담 및 심리치료장면에서 내담자들에게 긍정적인 도움을 줄 수 있다. 
이에 본 연구에서는 경로탐색을 위한 경로모델 검증과 매개효과를 통한 재 탐색 및 간 접효과유의성 모델검증을 통해 자기성찰, 마음챙김 다요인 및 마음챙김 자기효능감 그리 고 정신건강의 관계를 상세히 측정하였다. 그러나 본 연구의 제한점은 정신건강요인의 측정이 정신병리를 나타내는 사람들을 대상으로 측정하지않고 일반성인들을 대상으로 하 였다는데 제한점이 있다. 이에 정신건강을 측정한 간이정신진단검사의 9 개영역이 정신건 강의 상세한 분류체계를 지니지만 엄밀한 정신병리측정이 아님었음에 그 제한점이 있었 다. 이에 후속 연구에서는 마음챙김다요인의 하위요인별 정신건강의 상세분류체계별 간 의 상관성이 어떠한지를 측정하고, 단순 경로및 간접효과유의성에 그치지않고 구조방정 식 모형검증을 통한 유의성주장이 이루어져야 할 것이다. 그럼에도 불구하고 본 연구는 지금까지 이루어진 자기성찰, 마음챙김 및 정신건강에 대한 통계적 검증절차를 보완함으 로써 선행연구들의 관점을 보완할 수 있었다. 이에 본 연구의 내용이 임상 및 상담현장 에서 기초적 자료로써 유용하게 사용되기를 기대한다.

\section{References}

[1] Y. H. Yim, J. D. Kim, A Effect of self concept on mental health: The Pathway Model of multi-factor mindfulness and mindfulness-self-efficacy, The Journal of Humanities and Social science, (2019), Vol.10, No.1, pp.977-990, DOI: 10.22143/HSS21.10.1.68

[2] Y. H. You, Effect of Self concept and Self-reflect on Mental Health; Mediation Effect of Multi-factor Mindfulness and Mindfulness-Self-efficacy for University’s student, NungIn University, Master's Thesis, (2018)

[3] A. R. Baer, Mindfulness training as a clinical intervention: A conceptual and empirical review, Clinical Psychology, Science and Practice, (2003), Vol.10, No.2, pp.125-143, DOI: https://doi.org/10.1093/clipsy.bpg015

[4] H. C. Yong, A Effects of Mindfulness-Based Cognitive Therapy-Centering on Psychological Traits of Mothers with Handicapped Children, Daegu University, Doctoral Dissertation, (2008)

[5] S. H. Park, S. Y. Sung, The Moderating Effect of Mindfulness Between Self-Focused Attention and Psychological Well-Being, Korean Journal Of Counseling And Psychotherapy, (2008), Vol.20, No.4, pp.1127-1147, UCI: G704000523.2008.20.4.016

[6] S. L. Shapiro, L. E. Carlson, J. A. Astin, B. Freedman, Mechanism of mindfulness, Journal of Clinical Psychology, (2006), Vol.62, No.3, pp.373-386, DOI: https://doi.org/10.1002/jclp.20237

[7] J. Y. Hwang, Self-reflection scale development and a path model of self-reflection to well-being, Catholic University, Doctoral dissertation, (2011)

[8] Y. R. Kim, D. H. An, Development and validation of Multi-factor Mindfulness Scale for Adolescents (MMSA), The Journal of Educational Research, (2016), Vol.14, No.2, pp.25-51, UCI: G704-SER000010453.2016.14.2.004

[9] L. R. Derrogatis, R. S. Lipman, L. Covi, SCL-90: An outpatient psychiatric rating scale Preliminary report, Psychophamacology Bulletin, (1973), Vol.9, No.1, pp.13-28.

[10] K. I. Kim, J. H. Kim, H. T. Won, Korean manual of symptom checklist-90-revision, Seoul: Choung-Ang Juk-Sung Publishers, (1984)

[11] L. K . Muthén, B. O. Muthén, Mplus User's Guide, Los Angeles, California, Muthén and Muthén, (2011)

[12] P. E. Shrout, N. Bolger, Mediation in experimental and nonexperimental studies: new procedures and recommendations, Psychological methods, (2002), Vol.7, No.4, pp.422-445, DOI: https://doi.org/10.1037/1082989X.7.4.422 
[13] J. J. Miller, K. Flecher, J. Kabat-Zinn, Three-year follow-up and clinical implications of a mindfulness meditationbased stress reduction intervention in the treatment of anxiety disorders, General Hospital Psychiatry, (1995), Vol.17, No.3, pp.192-200, DOI: 10.1016/0163-8343(95)00025-m 